\title{
Interval duration and the sequential effects of reinforcement magnitude on FI performance
}

\author{
DONALD MELTZER \\ Southern Ilinois University, Carbondale, Illinois 62901 \\ and \\ D. LYNN HOWERTON \\ Arkansas State University, State University, Arkansas 72467
}

\begin{abstract}
Rats were reinforced on a fixed-interval schedule in which 3-min intervals alternated with 1-min intervals in even-numbered sessions and with 5-min intervals in odd-numbered sessions. The 1- and 5-min intervals ended with either one or three pellets. The number of responses in the 3-min interval was greater following one pellet than three pellets. There were also more responses during the 3-min interval when it alternated with a 1-min interval than when it alternated with a 5-min interval.
\end{abstract}

Several recent studies have shown that subjects reinforced on a fixed-interval (FI) schedule responded at higher rates during an interval following a small reinforcement than during an interval following a large reinforcement (Meltzer \& Howerton, 1973, 1975; Staddon, 1970). However, it is not known what effect interval duration has on this phenomenon, if any. The question can be asked with regard to several different duration parameters, but in this experiment it was decided to vary the duration of an interval, at the end of which a rat would receive either of two different amounts of reinforcement. The effects of interval duration and amount of reinforcement would then be determined by examining the subjects' responses during an alternating interval which was always of the same duration and which always ended with the same amount of reinforcement.

\section{METHOD}

\section{Subjects}

The subjects were nine male hooded rats, approximately 90 days old at the beginning of the experiment. Each animal was placed on a 22 -h food deprivation schedule 5 days before the beginning of the experiment and was maintained on that deprivation schedule until the experiment ended. Water was always available in an animal's home cage.

\footnotetext{
Apparatus

Each of the three identical chambers (Lehigh Valley Electronics No. 1316) had the following specifications. Interior dimensions were $21.0 \times 30.5 \times 18.0 \mathrm{~cm}$. A bar requiring a force of $18-20 \mathrm{~g}$ was located on the left side of the front wall, $3.5 \mathrm{~cm}$ above the grid floor. Food reinforcement consisted of one, two, or three $45-\mathrm{mg}$ Noyes pellets, delivered into a food hopper located in the middle of the front wall. If two or three pellets were to be delivered, the time between pellet presentations was no longer than $.5 \mathrm{sec}$. Two incandescent white lights, each emitting $37.1 \mathrm{fL}$ of illuminance, measured $2.5 \mathrm{~cm}$ from the source, were located on either side of the front wall $9.0 \mathrm{~cm}$ above the floor. A Knight pure-tone generator was used in
}

presenting an $830-\mathrm{Hz}$ tone, $3.5 \mathrm{~dB}$ above background noise, through a speaker mounted just outside the chamber.

White noise was present in the experimental room to mask extraneous sounds. Electromechanical programming and recording equipment was in an adjoining room.

\section{Procedure}

During the first three sessions, the rats were reinforced every time they pressed the bar. Beginning with the fourth session, all subjects were placed on an FI schedule. Two different multiple schedules were used for the rest of the experiment in alternate sessions. There were 17 fixed intervals in each session. In multiple schedule $A$ the cue light was always on during odd intervals: the first, third, fifth, etc. intervals in a session. These intervals were always 3 min long and always ended with a reinforcement consisting of two $45-\mathrm{mg}$ Noyes pellets delivered $.5 \mathrm{sec}$ apart. The light was always off during even-numbered intervals (i.e., the second, fourth, sixth, etc., intervals) and the tone was on.

The even-numbered intervals were $1 \mathrm{~min}$ long; four of them ended with a one-pellet reinforcement, while the other four ended with a 3-pellet reinforcement. The three pellets were delivered $.5 \mathrm{sec}$ apart. Thus, there were discriminative stimulilight plus no tone during 3 -min intervals, no light plus tone during $1-\mathrm{min}$ intervals-which allowed the subject to identify the duration of the current interval. There were no stimuli present that would have allowed the subject to predict the size of the reinforcement which would be delivered. We decided to use this procedure because previous work (Meltzer \& Howerton, 1975) had shown that there was a very small difference in performance following signaled as opposed to unsignaled variations in amount of reinforcement.

The sequence of one- and three-pellet reinforcements was arranged so that, if the intervening two-pellet reinforcement was ignored, a one-pellet reinforcement was equally likely to be followed by one pellet or three pellets at the end of the next 1 -min interval. And, in the same way, a three-pellet reinforcement was equally likely to be followed by one or three pellets at the end of the next 1-min session.

The alternate sessions, in which multiple schedule $B$ was used, also had a constant 3-min two-pellet light interval in every odd position. However, the even-numbered intervals were now 5 min long and neither light nor tone was on during these intervals. Thus, it was possible for the subject to discriminate between the 3-and 5-min intervals within these schedule $B$ 
Table 1

Response Rates During the First and Second Halves of the 1- and 5-Min Intervals

\begin{tabular}{ccc}
\hline Interval & First Half & Second Half \\
\hline 1 Min & 6.1 & 24.3 \\
$5 \mathrm{Min}$ & 8.3 & 19.1 \\
\hline
\end{tabular}

sessions and also to discriminate between the 5- and 1-min intervals between sessions. The 5-min intervals ended with either a one- or three-pellet reinforcement, just as the 1-min intervals did, and, just as in the 1-min intervals, there were no stimuli present that would allow the subject to predict the amount of reinforcement which would be delivered at the end of the current interval.

There were a total of 56 sessions during which the multiple schedules were used, 23 sessions with each schedule. The last 10 sessions using each schedule provided the data used in the analysis.

\section{RESULTS AND DISCUSSION}

The first analysis compared response rates in the first and second halves of the 1-and 5-min intervals, the evennumbered intervals in multiple schedule $A$ and multiple schedule B, respectively. The analysis was performed to insure that subjects were responding at significantly higher rates during the 1 -min intervals than during the 5 -min intervals. These mean rates are shown in Table 1. Response rate was significantly higher during the second half of the interval $(\mathrm{F}=51.47, \mathrm{df}=1 / 8, \mathrm{p}<.01)$, and there was a greater difference between response rates in the second half as opposed to the first half of the 1and 5-min intervals $(F=11.23, \mathrm{df}=1 / 8, \mathrm{p}<.025)$. In brief, this meant that there was very little difference between the mean response rate of 6.0 responses $/ \mathrm{min}$ during the first half of a 1-min interval and the mean of $8.3 \mathrm{responses} / \mathrm{min}$ during the first half of a 5 - $\mathrm{min}$ interval. However, mean response rate was 24.3 responses/ min during the last half of a 1-min interval and 19.1 responses/min during the last half of a 5-min interval. Apparently, subjects discriminated the two types of intervals but response rate differences were only present during the last half of each interval.

The second analysis examined the number of responses subjects made during the three time bins of the 3-min two-pellet intervals-the first $90 \mathrm{sec}$, the next $60 \mathrm{sec}$, and the last $30 \mathrm{sec}$. Number of responses was analyzed rather than response rate because, with time bins of unequal duration, overall rate measures would be distorted. However, the mean number of responses in an interval can be computed correctly regardless of the duration of the different time bins. Table 2 shows that there were different numbers of responses in each time bin, with the greatest number in the bin from 90 to $150 \sec (F=26.62, d f=2 / 16, p<.01)$. Subjects made a mean of 37.9 responses during each 3 -min interval following a one-pellet reinforcement and a mean of 31.6 responses during 3-min intervals following a threepellet reinforcement, which was a significant difference $(\mathrm{F}=18.30, \mathrm{df}=1 / 8, \mathrm{p}<.01)$. And, as Table 2 also shows, the difference in responses following one and three pellets was greatest during the second time bin of the interval, that is, between 90 and $150 \mathrm{sec}$ after the preceding reinforcement. This interaction was also significant $(\mathrm{F}=6.22, \mathrm{df}=2 / 16, \mathrm{p}<.05)$.

The duration of the variable reinforcement interval also had a significant effect on responses during the 3-min interval $(\mathrm{F}=9.26, \mathrm{df}=1 / 8, \mathrm{p}<.05)$. When the alternate interval was $1 \mathrm{~min}$ long, there were 42.3 responses during the 3-min interval. When the alternate interval was $5 \mathrm{~min}$ long, there was a mean of 27.0 responses during the 3-min interval. Finally, there was a significant interaction between the duration of the alternate interval and the distribution of responses during the 3-min interval $(\mathrm{F}=5.51, \mathrm{df}=2.16, \mathrm{p}<.05)$; as Table 2 shows, the greatest differences were again in the time bin between 90 and 150 sec.

Several points can be made regarding the data. First, subjects make more responses after small reinforcements than after large reinforcements, as has been demonstrated many times before. Second, the duration of an alternating interval in a complex multiple schedule has a strong inductive effect. Shorter alternate intervals increase responding; longer alternate intervals reduce it. However, these two effects do not interact. The differences in responding following large and small reinforcement are not affected by the duration of the interval at the end of which the variable reinforcement is delivered; nor does the duration of the interval at the end of which the variable reinforcement magnitude is delivered modify the effects of reinforcement magnitude on response output during the next interval.

Finally, both of these effects are smallest at the beginning of an interval when a subject is responding at a very low rate and at the end of an interval when a subject is responding at a high terminal rate. They are greatest during the middle of the interval.

Table 2

Mean Number of Responses During Successive Time Bins in Different Types of 3-Min Intervals Ending with a Two-Pellet Reinforcement

\begin{tabular}{|c|c|c|c|c|c|}
\hline \multirow[b]{2}{*}{ Time Bin } & \multirow[b]{2}{*}{$\begin{array}{c}\text { All } \\
\text { Intervals }\end{array}$} & \multicolumn{2}{|c|}{$\begin{array}{l}\text { Alternate } \\
\text { Interval } \\
\text { Duration }\end{array}$} & \multicolumn{2}{|c|}{$\begin{array}{c}\text { Size of } \\
\text { Last } \\
\text { Reinforcement }\end{array}$} \\
\hline & & $1 \mathrm{Min}$ & $5 \mathrm{Min}$ & $\begin{array}{c}\text { One } \\
\text { Pellet }\end{array}$ & $\begin{array}{r}\text { Three } \\
\text { Pellets }\end{array}$ \\
\hline $\begin{array}{r}0-90 \mathrm{sec} \\
90-150 \mathrm{sec} \\
150-180 \mathrm{sec}\end{array}$ & $\begin{array}{r}7.4 \\
15.5 \\
11.8\end{array}$ & $\begin{array}{r}9.8 \\
19.0 \\
13.5\end{array}$ & $\begin{array}{r}5.0 \\
12.0 \\
10.0\end{array}$ & $\begin{array}{r}8.8 \\
17.2 \\
11.9\end{array}$ & $\begin{array}{r}6.1 \\
13.9 \\
11.6\end{array}$ \\
\hline $0-180 \mathrm{sec}$ & 34.7 & 42.3 & 27.0 & 37.9 & 31.6 \\
\hline
\end{tabular}




\section{REFERENCES}

Meltzer, D.. \& Howerton, D. L. Sequential effects of reinforcement magnitude on fixed-interval performance. Journal of Comparative and Physiological Psychology, 1973, 85, 361-366.

Meltzer. D.. \& Howerton, D. L. Sequential effects of signaled and unsignaled variations in reinforcement magnitude on fixed interval performance. Bulletin of the Psychonomic Society. 1975, 6, 461-464.

Staddon. J. E. R. Effects of reinforcement duration in fixed interval responding. Journal of the Experimental Anulisis of Behavior, 1970, 13, 9-11.

(Received for publication June 5, 1976.) 